\title{
Drug Non-Adherence And Reasons Among Multidrug-Resistant Tuberculosis Patients In Guizhou, China: A Cross-Sectional Study
}

This article was published in the following Dove Press journal: Patient Preference and Adherence

\author{
Yun Wang ${ }^{1,2}$ \\ Huijuan Chen ${ }^{3}$ \\ Zhongfeng Huang ${ }^{4}$ \\ Edward B McNeil (D) ${ }^{2}$ \\ Xiaolong $\mathrm{Lu}^{\prime}$ \\ Virasakdi \\ Chongsuvivatwong (iD) ${ }^{2}$ \\ 'School of Medicine and Health \\ Management, Guizhou Medical \\ University, Guiyang, Guizhou, People's \\ Republic of China; 'Epidemiology Unit, \\ Faculty of Medicine, Prince of Songkla \\ University, Hat Yai, Songkhla, Thailand; \\ ${ }^{3}$ Department of Tuberculosis Prevention \\ and Control, Guizhou Center for Disease \\ Prevention and Control, Guiyang, \\ Guizhou, People's Republic of China; \\ ${ }^{4}$ Department of Tuberculosis, Guiyang \\ Public Health Clinical Center, Guiyang, \\ Guizhou, People's Republic of China
}

Correspondence: Virasakdi

Chongsuvivatwong

Epidemiology Unit, Faculty of Medicine,

Prince of Songkla University, 15

Kanchanawanit Road, Hat Yai, Songkhla, Thailand

Tel +66 74429754

Fax +6674212900

Email cvirasak@medicine.psu.ac.th
Purpose: Treatment interruption and incorrect dosage for measuring drug non-adherence have seldom been studied in multidrug-resistant tuberculosis (MDR-TB) treatment. This study aimed to 1 ) estimate the overall and drug-specific incidence of short ( $\leq 14$ days) and serious ( $>14$ days) treatment interruption among MDR-TB patients, 2) identify main reasons and predictors for serious interruption, and 3) document the level of agreement of classification for incorrect drug dosage between self-report and pill count.

Patients and methods: A cross-sectional study combining hospital-based interviews and home-based pill count was conducted from January to June 2018. Treatment interruption was determined from patient's medical records and interviews using a structured questionnaire among 202 patients treated at one designated hospital for MDR-TB treatment. Concordance of pills counted with self-reports for each drug use within one month was assessed for a subgroup of patients at their homes using kappa statistics.

Results: Of 202 patients, the incidence of short and serious treatment interruption was $37.6 \%$ and $28.7 \%$, respectively. Adverse drug reactions (ADRs) and financial hardship were the top two reasons for serious interruption. Amikacin and cycloserine had the highest rate of specific drug interruption (18.3\% and 10.2\%, respectively). ADRs (OR adj: $2.82,95 \% \mathrm{CI}$ : 1.41-5.61), monthly out-of-pocket expenses exceeding $250 \mathrm{US}$ dollars $\left(\mathrm{OR}_{\mathrm{adj}}: 2.27,95 \% \mathrm{CI}\right.$ : 1.14-4.50), and baseline co-morbidities ( $\left.\mathrm{OR}_{\mathrm{adj}}: 2.53,95 \% \mathrm{CI}: 1.19-5.38\right)$ were significantly associated with serious treatment interruption. Of 111 patients assessed for pill count at home, 5.4\% had perfect drug adherence, $54.1 \%$ had drug under-use, $6.3 \%$ had drug over-use, and $34.2 \%$ had both problems. The respective number from self-reports was $7.2 \%, 56.8 \%$, $5.4 \%$ and $30.6 \%$. The two methods gave an acceptable level of agreement for most of the drugs (kappa: 0.52-0.95).

Conclusion: Close monitoring of ADRs, revision of drug regimens, and financial support for MDR-TB in this study population are needed. Self-report on drug under-use and over-use should be monitored monthly in clinical settings.

Keywords: multidrug-resistant tuberculosis, adherence, treatment interruption, Guizhou

\section{Plain Language Summary}

Multidrug-resistant tuberculosis (MDR-TB) is a chronic infectious disease spread via the air. Treatment interruption as well as under- and overuse of drugs can cause treatment failure which further spreads the disease. It is important to quantify the magnitude of the problem and understand the underlying reasons for non-adherence to treatment as it will help to adopt targeted interventions for improving adherence and reducing the transmission of MDR-TB. Therefore, we conducted a hospital- and home-based study from January to June in 2018 to 
investigate these problems in Guizhou, an endemic area for MDRTB. We found that over a quarter of the 202 patients recruited from the hospital had their treatment interrupted for more than 14 days. Adverse drug reactions (ADRs), high monthly out-of-pocket drug costs, and having a baseline co-morbidity were associated with serious interruption ( $>14$ days). The main reasons for serious interruption were ADRs and high drug costs. Of 111 patients who were assessed with pill count at home, 5.4\% had perfect drug adherence, $54.1 \%$ had drug underuse, $6.3 \%$ had drug overuse, and $34.2 \%$ had both problems within 1 month. Pill count agreed well with self-reports. Based on these findings, we recommend that ADRs be monitored closely, drug regimens be revised, and financial support given for MDR-TB patients. Patients should be interviewed monthly by nurses about drug under- and over-use in clinical settings.

\section{Introduction}

Multidrug-resistant tuberculosis (MDR-TB) is a chronic infectious disease spread via the air, which is caused by Mycobacterium tuberculosis (MTB) and is resistant to at least two anti-TB drugs: isoniazid and rifampin. ${ }^{1}$ Standard treatment for MDR-TB consists of a multidrug regimen lasting for 24 months. ${ }^{2}$ Successful cure of patients is crucial for controlling the MDR-TB epidemic. ${ }^{2}$ However, non-adherence to treatment is an important barrier to treatment success. ${ }^{3,4}$ In 2017, 457,560 people were estimated to be affected by MDR-TB globally, and the treatment success rate was only $55 \% .{ }^{1}$ Treatment failure promotes further transmission of MDR-TB and development of extensively drug-resistant TB. ${ }^{1}$ Thus, it is important to quantify the incidence of drug non-adherence in these patients and understand their underlying reasons for non-adherence as it will contribute to the implementation of targeted interventions.

Treatment interruption and drug under- and over-use are important indicators for measuring drug non-adherence and have seldom been studied in MDR-TB treatment. To our knowledge, only four studies have reported data on treatment interruption among patients with MDRTB. ${ }^{3-6}$ Treatment interruption was defined as an interruption of any anti-TB drug for at least one day at any time during the treatment course while a serious treatment interruption lasting for more than two consecutive weeks but less than two consecutive months. ${ }^{3,5,6}$ The incidence of treatment interruption ranged from $68 \%$ to $93 \%$ and the incidence of serious interruption was $17 \%^{6}$ and $27 \%{ }^{5}$ Serious treatment interruption was demonstrated to be associated with unsuccessful treatment outcome. ${ }^{3,4}$ Only one study explored predictors of treatment interruption, which were found to be gender, education level, and directly observed treatment (DOT) coverage. ${ }^{6}$ Only two studies documented the main reasons for treatment interruption, including patient absence, ${ }^{4}$ treatment refusal, ${ }^{4}$ and adverse drug reactions (ADRs). ${ }^{6}$ Therefore, more studies need to be conducted to explore in depth the predictors and reasons for serious interruption, especially the impact of specific drugs on serious interruption.

Patients who take their drugs every day may still take the incorrect dose. Pill count at the patients' home can be adopted to assess this indicator. Home visits were used because counting pills at the clinic can be cumbersome, especially if there are many pills to count and the clinic is busy. ${ }^{7}$ But pill count by home visits consumes many resources. Thus, whether this is necessary for MDR-TB patients needs to be tested. If patients' reports agree well with pill counts, the need to spend time and resources on the latter procedure can be reduced.

China has the second highest MDR-TB burden in the world after India. ${ }^{1}$ The number of MDR-TB patients enrolled under treatment of the national TB program networks was 5691 in $2015^{8}$ and the treatment success rate was only $41 \%{ }^{1}$ Among the 34 provincial-level administrative divisions of China, Guizhou is one of the lowincome provinces in southwest China with a population of 35 million and the third highest TB incidence. ${ }^{9}$ It is therefore an appropriate place to examine drug nonadherence.

The objectives of this study were 1) to estimate the overall and drug-specific incidence of short ( $\leq 14$ days) and serious ( $>14$ days) treatment interruption among multidrug-resistant tuberculosis (MDR-TB) patients, 2) to identify main reasons and predictors for serious interruption, and 3) to document the level of agreement of classification for incorrect drug dosage as assessed by self-report and pill count.

\section{Materials And Methods}

\section{Study Design And Setting}

A cross-sectional study combining hospital-based patient interviews and home-based pill counts was conducted from January to June 2018. Participants were recruited from Guiyang Public Health Clinical Center (GPHCC), one of the only two hospitals designated for MDR-TB 
diagnosis and treatment in Guizhou. ${ }^{10}$ Three-quarters of all MDR-TB patients in the whole province are diagnosed and treated at this institution each year.

\section{MDR-TB Regimen}

A 24-month regimen was implemented in GPHCC according to the national guideline for MDR-TB treatment issued in 2012. ${ }^{11}$ Treatment duration consists of a 6-month intensive phase followed by an 18 -month continuation phase. One injectable drug is given during the intensive phase and at least four oral drugs are prescribed over the whole course of treatment.

Five groups of drugs for MDR-TB treatment, except kanamycin, are included into China's national essential drug list ${ }^{12}$ and basic medical insurance list. ${ }^{13}$ Their daily dosages, ${ }^{11}$ monthly cost, ${ }^{14}$ classification in the basic medical insurance list, ${ }^{13}$ and reimbursement coverage ${ }^{15}$ are shown in Table 1. Of the 15 drugs, 10 are recommended in the standardized treatment regimen by the national guideline, ${ }^{11}$ including three kinds of injectable drugs (kanamycin, amikacin, and capreomycin) and seven kinds of oral drugs (pyrazinamide, levofloxacin, moxifloxacin, cycloserine, p-aminosalicylic acid, ethambutol, and prothionamide). Of these, five (kanamycin, pyrazinamide, levofloxacin, cycloserine, and prothionamide) are preferred drugs and the others are alternatives.

\section{Medical Insurance}

There are currently three basic medical insurance systems in Guizhou: the New Rural Cooperative Medical Scheme (NRCMS) for rural residents, the Urban Employee Basic Medical Insurance (UEBMI) for formal sector employees living/working in urban areas, and the Urban Resident Basic Medical Insurance (URBMI) for other urban residents. ${ }^{16}$ MDR-TB is covered by a case-based payments package in NRCMS with a maximum liability of 18,000 yuan per year per patient and is also included in specific outpatient reimbursement in UEBMI (average 75\% reimbursement ratio with 800 yuan deductibles and 12,000 yuan ceiling per year) and URBMI schemes (average $35 \%$ reimbursement ratio with 600 yuan deductibles and 300,000 yuan ceiling per year). Drug costs account for about $53 \%$ of the total costs and $79 \%$ of the outpatient costs. ${ }^{17}$ Incomplete reimbursement results in some financial burden to the patients and their family as some drugs are quite costly.

\section{Participants And Sample Size}

All patients diagnosed with MDR-TB by drug susceptibility testing from 2016 to 2017 in GPHCC and currently receiving treatment were included. Patients who agreed to participate in the study were interviewed face-to-face after obtaining written informed consent by a trained research team in the hospital or at their home. Their medical records were retrieved. The sample size of the study $(n=167)$ was calculated based on the incidence of treatment interruption $(68 \%)^{6}$ with $95 \%$ confidence limits from the estimate.

\section{Recruitment Of Participants}

A total of 268 MDR-TB patients were registered in GPHCC during 2016 and 2017, of which 233 were still under treatment. Of these, $202(86.7 \%)$ agreed to participate in the study and were interviewed using a questionnaire. Overall, $180(89 \%)$ participants who resided in 6 accessible prefectures were approached by the research team. Of these, 49 could not be contacted due to incorrect address and telephone information, 19 refused, and 1 died. The remaining 111 patients were visited at their homes where researchers collected information on drug adherence within last month using self-reports and pill counts.

\section{Variable Definitions}

Treatment interruption was defined as any interruption lasting at least one day at any time during the treatment course. ${ }^{3-6}$ Any interruption lasting more than two consecutive weeks was defined as a serious treatment interruption. ${ }^{6}$ If the patient had more than one interruption, the longest period was considered and recorded. Our information has drug-specific interruption and complete interruption of all drugs for individual patients.

Participants were classified as having correct drug use if the number of pills actually taken was the same as the number of pills expected to be taken, under-use if the number of pills actually taken was less than the number of pills expected to be taken, and over-use if the number of pills actually taken was more than the number of pills expected to be taken.

\section{Data Collection}

Data collection was divided into two parts based on the outcome variables mentioned earlier.

In the first part, data were extracted from medical records and a structured questionnaire at the hospital. The duration of treatment interruption and drugs taken were 


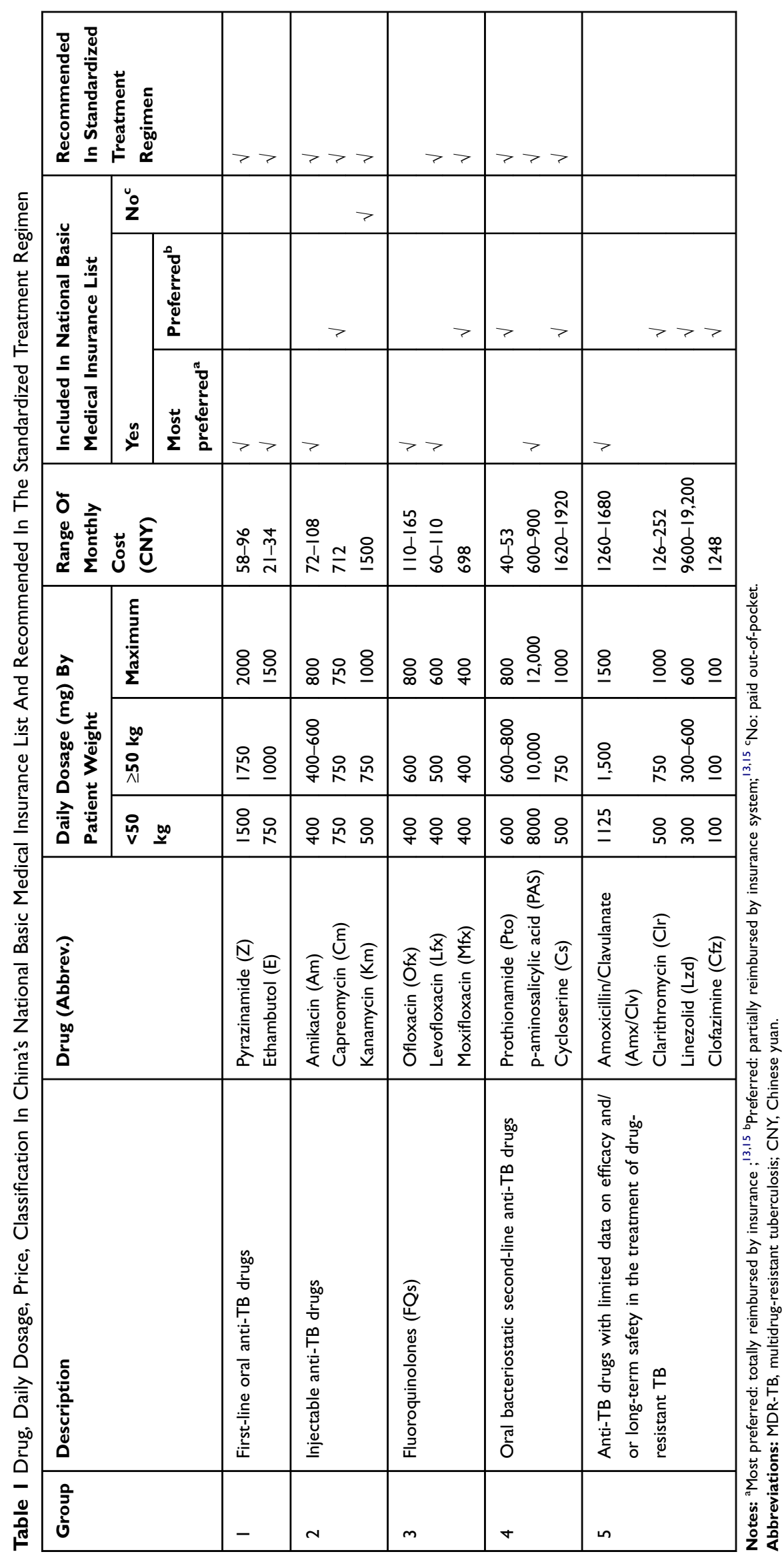


obtained from the medical records. For each patient, we counted the days of consecutive interruption since initiation of treatment. If the patient had more than one interruption, the longest period was considered, and the $\operatorname{drug}(\mathrm{s})$ interrupted during this period were recorded. Demographic characteristics (gender, age, ethnicity, occupation before diagnosis of MDR-TB, and area of residence) and clinical information (classification of MDR-TB, baseline weight and co-morbidity, length of treatment, and ADR) were obtained from medical records. The price of some secondline drugs not listed in the Guide Price List of National Essential Drugs ${ }^{14}$ was obtained from the electronic hospital medical database. The main reason for the longest interruption, the injection delivery route, injection fee, and other explanatory variables for treatment interruption were obtained from the structured questionnaire, including 1) demographic characteristics (marital status, education level, occupation after MDR-TB); 2) financial status due to MDR-TB; 3) household information (annual income, annual expenditure, family size, insurance scheme); and 4) DOT coverage.

In the second part, the process of home visits was done as follows: the telephone numbers and addresses of the patients were obtained from the hospital. Local village doctors helped to make appointments, but patients and their family had not been informed in advance about the pill count. The interview team, which consisted of staff from the local Center for Disease Control, were trained before collecting data. During home visits, the interview team informed the participants of the study objectives. After obtaining written informed consent, pills per time and times per day for each drug by self-report were collected firstly by one team member, and then two members of the team counted the pills left and recorded the results. The time interval of drug use was from the date of home visit to the date of last prescription. Patients visited the hospital every month to receive their drugs. The receipts from the hospital were inspected to confirm the date of last prescription and the number of drugs prescribed.

\section{Statistical Analysis}

Data were entered into EpiData (version: 3.1, Odense, Denmark) and analyzed using $\mathrm{R}$ (version 3.4.2, Vienna, Austria). Descriptive statistics are presented using medians with interquartile range (IQR) and mean with standard deviation (SD) as appropriate for continuous variables and frequencies with percentage otherwise. Variables associated with serious treatment interruption ( $>14$ days) were explored first by univariate analyses. Variables with a P-value below 0.2 were included in the initial multivariate logistic regression modeling process. $\mathrm{P}$-values from the likelihood ratio test were assessed at each step and used to determine the final model where variables with a P-value less than 0.05 remained. The prevalence-adjusted kappa statistic for ordinal variables was computed to determine the level of agreement between D1 and D2, described next.

D1 is the discrepancy between the expected number of pills taken and number of pills taken from self-report while D2 is the discrepancy between the expected number of pills taken and number of pills taken from the pill count. They were calculated based on five variables: 1) Time interval (T): number of days between the date of home visiting and the date of last prescription; 2) Number of pills expected to be taken per day $(\mathrm{E})$ : recommended dosage from the national guideline; 3) Number of pills per day for each drug taken by self-report (NS): pills per time multiplying by times per day; and 4) Number of pills taken by pill count: the difference between number of pills taken from last prescription (LP) and number of pills left (NL). Consequently, D1 $=\mathrm{E} \times \mathrm{T}-\mathrm{NS} \times \mathrm{T}$ and $\mathrm{D} 2=\mathrm{E} \times \mathrm{T}-(\mathrm{LP}-\mathrm{NL})$.

\section{Ethical Consideration}

The study protocol was approved by the Institutional Ethics Committee of the Faculty of Medicine, Prince Songkla University, Thailand (REC:60-338-18-1) and the Ethics Committee of Guiyang Public Health Clinical Center, Guiyang, Guizhou province, China.

\section{Results}

\section{Characteristics Of Patients}

Demographic characteristics of the three groups of patients are shown in Table 2. The first group includes all patients registered in the hospital $(n=268)$. The second group includes only those interviewed at the hospital $(n=202)$, which was a subset of the first group. The third group includes only those from group 2 who were interviewed at their home $(n=111)$. The distribution of gender, age, ethnicity, occupation before diagnosis of MDR-TB, area of residence, classification of MDR-TB, and duration of treatment was similar between the three groups. Information obtained from the questionnaire, which was not available for the first group, was similar between the second and third groups.

For the three groups, the majority of patients were young to middle-aged males living in rural areas. The proportion of unemployed patients was around $10 \%$ before 
Table 2 Comparison Of Patient Characteristics Among The Three Groups

\begin{tabular}{|c|c|c|c|}
\hline \multirow[t]{2}{*}{ Characteristic } & $\begin{array}{l}\text { Total } \\
\text { Registered } \\
\text { Patients } \\
\text { At The } \\
\text { Hospital } \\
(n=268)\end{array}$ & $\begin{array}{l}\text { Patients } \\
\text { Interviewed } \\
\text { At The } \\
\text { Hospital } \\
(n=202)\end{array}$ & $\begin{array}{l}\text { Patients } \\
\text { Interviewed } \\
\text { At Their } \\
\text { Home } \\
(n=111)\end{array}$ \\
\hline & n (\%) & n (\%) & n (\%) \\
\hline \multicolumn{4}{|l|}{ Gender } \\
\hline Female & $83(31.0)$ & $67(33.2)$ & $34(30.6)$ \\
\hline Male & $185(69.0)$ & $135(66.8)$ & $77(69.4)$ \\
\hline Age (Median, IQR) & $37(27,49)$ & $36(26,48)$ & $38(27,48)$ \\
\hline \multicolumn{4}{|l|}{ Ethnic group } \\
\hline Han & $199(74.3)$ & $140(69.3)$ & $83(74.8)$ \\
\hline Other & $69(25.7)$ & $62(30.7)$ & $28(25.2)$ \\
\hline \multicolumn{4}{|c|}{ Occupation before MDR-TB } \\
\hline Migrant worker & $55(20.5)$ & $52(25.7)$ & $26(23.4)$ \\
\hline Farmer & $103(38.4)$ & $61(30.2)$ & $40(36.0)$ \\
\hline Government worker & $15(5.6)$ & $15(7.4)$ & $5(4.5)$ \\
\hline Company worker & $37(13.8)$ & $37(18.3)$ & $17(15.3)$ \\
\hline Student & $26(9.7)$ & $26(12.9)$ & $16(14.4)$ \\
\hline Unemployed & $32(11.9)$ & II (5.4) & $7(6.3)$ \\
\hline \multicolumn{4}{|l|}{ Area of residence } \\
\hline Urban & $46(17.2)$ & $4 \mid(20.3)$ & $19(17.1)$ \\
\hline Rural & $222(82.8)$ & $161(79.7)$ & $92(82.9)$ \\
\hline \multicolumn{4}{|l|}{ Classification of MDR-TB } \\
\hline Primary & $24(9.0)$ & $21(10.4)$ & II (9.9) \\
\hline Secondary & $244(91.0)$ & $181(89.6)$ & $100(90.1)$ \\
\hline \multicolumn{4}{|c|}{ Duration of treatment (months) } \\
\hline$<12$ & $76(28.4)$ & $60(29.7)$ & $35(3 \mid .5)$ \\
\hline $12-24$ & $192(71.6)$ & $142(70.3)$ & $76(68.5)$ \\
\hline \multicolumn{4}{|l|}{ Marital status } \\
\hline Single & - & $78(38.6)$ & $38(34.2)$ \\
\hline Married & - & $124(6 \mid .4)$ & $73(65.8)$ \\
\hline \multicolumn{4}{|l|}{ Education level } \\
\hline Primary school or less & - & $60(29.7)$ & $39(35.1)$ \\
\hline Middle school & - & $68(33.7)$ & $30(27.0)$ \\
\hline High school & - & $55(27.2)$ & $35(31.5)$ \\
\hline University & - & $19(9.4)$ & $7(6.3)$ \\
\hline \multicolumn{4}{|c|}{ Occupational status after getting MDR-TB } \\
\hline Still working & - & $62(30.7)$ & $31(27.9)$ \\
\hline $\begin{array}{l}\text { Lost job or could not } \\
\text { work }\end{array}$ & - & $103(51.0)$ & $57(5 \mid .4)$ \\
\hline Student/unemployed & - & $37(18.3)$ & $23(20.7)$ \\
\hline
\end{tabular}

(Continued)
Table 2 (Continued).

\begin{tabular}{|c|c|c|c|}
\hline Characteristic & $\begin{array}{l}\text { Total } \\
\text { Registered } \\
\text { Patients } \\
\text { At The } \\
\text { Hospital } \\
(n=268)\end{array}$ & $\begin{array}{l}\text { Patients } \\
\text { Interviewed } \\
\text { At The } \\
\text { Hospital } \\
(n=202)\end{array}$ & $\begin{array}{l}\text { Patients } \\
\text { Interviewed } \\
\text { At Their } \\
\text { Home } \\
(n=I I I)\end{array}$ \\
\hline & n (\%) & n (\%) & n (\%) \\
\hline $\begin{array}{c}\text { Per capita annual } \\
\text { income (Median, IQR) }\end{array}$ & - & $\begin{array}{l}1761(1172 \\
3258)\end{array}$ & $\begin{array}{l}1574(1003 \\
3168)\end{array}$ \\
\hline \multicolumn{4}{|l|}{ Insurance scheme } \\
\hline $\begin{array}{l}\text { UEBMI } \\
\text { URBMI } \\
\text { NRCMS } \\
\text { None }\end{array}$ & $\begin{array}{l}- \\
- \\
-\end{array}$ & $\begin{array}{l}22(10.9) \\
6(3.0) \\
169(83.7) \\
5(2.5)\end{array}$ & $\begin{array}{l}8(7.2) \\
4(3.6) \\
99(89.2) \\
0\end{array}$ \\
\hline $\begin{array}{l}\text { Monthly drug costs } \\
\text { before reimbursement } \\
\text { (Mean, SD) } \\
\text { Monthly OOP of drug } \\
\text { costs (Mean, SD) } \\
\text { In debt due to MDR-TB }\end{array}$ & - & $\begin{array}{l}240.6,160.2 \\
149.5,157.3 \\
120(59.4)\end{array}$ & $\begin{array}{l}245.4,166.6 \\
152.6,166.2 \\
66(59.5)\end{array}$ \\
\hline Received DOT & - & $56(27.7)$ & $30(27.0)$ \\
\hline Baseline co-morbidity & _- & $40(19.8)$ & $27(24.3)$ \\
\hline DM & - & $18(8.9)$ & $12(10.8)$ \\
\hline Hepatitis B & - & $6(3.0)$ & $3(2.7)$ \\
\hline COPD & - & $5(2.5)$ & $4(3.6)$ \\
\hline Others $^{\mathrm{a}}$ & - & II (5.4) & $8(7.2)$ \\
\hline
\end{tabular}

Notes: All costs are in United States dollars. Column 2 is a subgroup of column I,

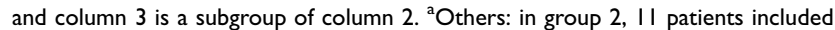
gastritis $(n=3)$, uarthritis $(n=3)$, hypertension $(n=2)$, hyperuricemia $(n=2)$, coronary heart disease $(n=1)$. In group 3, 8 patients included gastritis $(n=2)$, uarthritis $(n=2)$, hypertension $(n=1)$, hyperuricemia $(n=2)$, coronary heart disease $(n=1)$.

Abbreviations: DOT, directly observed treatment; IQR, interquartile range; SD, standard deviation; MDR-TB, multidrug-resistant tuberculosis; NRCMS, New Rural Cooperative Medical Scheme; OOP, out-of-pocket; UEBMI, Urban Employee Basic Medical Insurance; URBMI, Urban Resident Basic Medical Insurance; DM, diabetes; COPD, chronic obstructive pulmonary disease.

diagnosis. Ninety percent were secondary cases and $71.6 \%$ had finished 1 year of treatment at the time of interview. For groups 2 and 3, most patients were married and had a low educational level. Half either lost their job or could not work after diagnosis of MDR-TB. The median (IQR) per capita annual income was US\$1761 (1172-3258) in group 2 and US\$1574 (1003-3168) in group 3. The cost of treatment for $97.5 \%$ of the patients was partially covered by medical insurance. The mean values of monthly drug costs were similar between group 2 and 3 (US\$ 240.6 vs US\$ 245.4), and so were out-of-pocket (OOP) drug costs (US\$ 149.5 vs US\$ 152.6). On average, patients had to pay $62 \%$ of the drug costs OOP per month and $59 \%$ of the patients were in debt due to MDR-TB treatment. Less than 
one-third of the patients underwent DOT. Around $20 \%$ of the patients in both groups had a co-morbidity at baseline with diabetes being the most common.

\section{Treatment Interruption And Reasons For Serious Treatment Interruption}

Table 3 presents frequency of short and serious treatment interruption among 202 patients and main reason for serious interruption by specific drug received. The total number of patients with any interruption is in column a, which is the sum of column b (short interruption) and column c (serious interruption). Columns $\mathrm{d}$, e, and $\mathrm{f}$ contain the main reasons for serious interruption, and their sum is shown in column c. The overall incidence of short treatment interruption ( $\leq 14$ days) was $37.6 \%$, and serious interruption ( $>14$ days) was $28.7 \%$. ADRs and financial hardship accounted for $20.3 \%$ and $5.4 \%$ of the serious interruptions, respectively. For drug-specific interruption, amikacin, the only injectable drug used in the intensive phase, was the most commonly interrupted drug (18.3\%) followed by cycloserine $(10.2 \%)$ and pyrazinamide (2.4\%). Of all 58 patients (28.7\%) with a serious interruption, nearly a half had completely interruption of all drugs.

\section{Predictors For Serious Treatment Interruption}

Table 4 shows predictors of serious treatment interruption by univariate and multivariate analysis. Three variables remained significant on multivariate analysis, namely patients with monthly out-of-pocket expenses exceeding 250 US dollars ( $\mathrm{OR}_{\text {adj: }}$ :2.27, 95\% CI: 1.14 4.50), patients with a baseline co-morbidity ( $\mathrm{OR}_{\text {adj }}$ : 2.53, 95\% CI: 1.19-5.38), and patients who experienced an $\mathrm{ADR}$ during their treatment ( $\mathrm{OR}_{\mathrm{adj}}: 2.82$, 95\% CI: $1.41-5.61)$.

\section{Agreement Between Self-Report And Pill Count}

Table 5 presents the level of agreement for each drug between self-report (row-wise) and pill count (columnwise) among the 111 patients who were visited at home. For each sub-table, the values in the diagonal cells from left upper corner to right lower corner indicate the number of subjects with agreement in assessment by these two methods. These values were computed against agreement by chance and the kappa static was obtained. ${ }^{18}$ The first small table shows the results for amikacin. Thirty-two patients were still under treatment in their intensive phase. There were 31 patients $(19+7+5)$ having agreement by the two methods giving a kappa of 0.95 , which indicates a high level of agreement. For other sub-tables, the number of patients taking oral drugs varied depending on the patient's regimen. The kappa static for these oral drugs ranged from 0.88 to 0.52 . Thus, the two methods gave acceptable levels of agreement for most of the drugs. The rate of correct drug dose use for all drugs assessed by self-report was higher than that measured by pill counts. Of the 111 patients, $5.4 \%$ had perfect drug adherence, $54.1 \%$ had drug under-use, $6.3 \%$ had drug over-use, and $34.2 \%$ had both problems as assessed by pill count. The respective figures from self-report were $7.2 \%, 56.8 \%, 5.4 \%$, and $30.6 \%$ (kappa static $=0.66)$.

\section{Discussion}

Our study demonstrates that more than one-third of the patients had a short treatment interruption and 28.7\% experienced a serious interruption. ADRs and financial hardship were the top two reasons for serious interruption according to the patients themselves. Amikacin and cycloserine were the two most attributable drugs for specific drug interruption. The former was the most commonly used and interrupted drug due to its high occurrence of adverse events, and the latter was often interrupted mostly because of its high cost. Patients had an increased odds of serious interruption by a factor of 2.8 if they had an adverse reaction to any drug, by a factor of 2.3 if the monthly OOP drug expense exceeded 250 US dollars, and by a factor of 2.5 if they had any co-morbidity prior to commencing treatment. Less than $10 \%$ of the patients took their drugs at the correct dose due to high rates of under-use. Self-reports and pill count gave acceptable levels of agreement for most of the drugs used.

A study from Shandong in China showed that $51 \%$ of the MDR-TB patients had short treatment interruptions, and $17 \%$ had serious interruptions. In that study, $50 \%$ of the patients underwent DOT and these patients had less serious interruptions than those who did not undergo DOT. $^{6}$ The low DOT coverage $(27.7 \%)$ in our study may be one of the potential reasons for the higher incidence of serious interruption. Considering the positive impact of DOT on treatment interruption, the practice of DOT needs to be provided to patients throughout the duration of MDR-TB treatment as recommended by WHO. ${ }^{2}$ 
Table 3 Frequency Of Treatment Interruption And Main Reason For Serious Interruption By Specific Drug Received ( $\mathrm{n}=202$ Patients)

\begin{tabular}{|c|c|c|c|c|c|c|c|}
\hline \multirow[t]{2}{*}{$\begin{array}{l}\text { Type Of Interruption And } \\
\text { Specific Drug Interrupted }\end{array}$} & \multirow{2}{*}{$\begin{array}{l}\text { Number Of } \\
\text { Patients } \\
\text { Under } \\
\text { Treatment By } \\
\text { Drug } \\
\text { Received }\end{array}$} & \multirow{2}{*}{$\begin{array}{l}\text { Number Of } \\
\text { Patients } \\
\text { With } \\
\text { Interruption } \\
\text { n (\%) }(a=b+c)\end{array}$} & \multicolumn{2}{|c|}{$\begin{array}{l}\text { Duration Of Interruption } \\
\text { n (\%) }\end{array}$} & \multicolumn{3}{|c|}{$\begin{array}{l}\text { Main Reason For Serious } \\
\text { Interruption, } \mathbf{n}(\%)\end{array}$} \\
\hline & & & $\begin{array}{l}\text { Short } \\
\text { Interruption } \\
\text { (I-I4 Days) } \\
\text { (b) }\end{array}$ & $\begin{array}{l}\text { Serious } \\
\text { interruption } \\
(>14 \text { days }) \\
(c=d+e+f)\end{array}$ & $\begin{array}{l}\text { Adverse } \\
\text { Drug } \\
\text { Reaction }^{a} \\
\text { (d) }\end{array}$ & $\begin{array}{l}\text { Financial } \\
\text { Hardship } \\
\text { (e) }\end{array}$ & $\begin{array}{l}\text { Other } \\
\text { (f) }\end{array}$ \\
\hline Overall & 202 & $134(66.3)$ & $76(37.6)$ & $58(28.7)$ & $4 \mathrm{I}(20.3)$ & II (5.4) & $6(3.0)$ \\
\hline Single drug interruption & 202 & $48(23.8)$ & $20(9.9)$ & $28(13.9)$ & $23(\mathrm{II} .4)$ & $5(2.5)$ & $0(0.0)$ \\
\hline Amikacin & 202 & $37(18.3)$ & $16(7.9)$ & $21(10.4)$ & $21(10.4)$ & $0(0.0)$ & $0(0.0)$ \\
\hline Cycloserine & 59 & $6(10.2)$ & $\mathrm{I}(\mathrm{I} .7)$ & $5(8.5)$ & $0(0.0)$ & $5(8.5)$ & $0(0.0)$ \\
\hline Pyrazinamide & 169 & $4(2.4)$ & $2(1.2)$ & $2(1.2)$ & $2(1.2)$ & $0(0.0)$ & $0(0.0)$ \\
\hline Amoxicillin/Clavulanate & 35 & I (2.9) & $\mathrm{I}(2.8)$ & $0(0.0)$ & $0(0.0)$ & $0(0.0)$ & $0(0.0)$ \\
\hline Completely drug interruption & 202 & $86(42.6)$ & $56(27.7)$ & $30(14.9)$ & $18(8.9)$ & $6(3.0)$ & $6(3.0)$ \\
\hline
\end{tabular}

Notes: adverse drug reaction: hepatotoxicity $(n=13)$, hematoma/pain at the injection site $(n=12)$, ototoxicity $(n=9)$, gastrointestinal disturbance $(n=4)$, erythra $(n=2)$, and dizziness $(n=1)$. ${ }^{b}$ Others include feeling better $(n=3)$, no confidence in treatment $(n=2)$, and insufficient drug $(n=1)$.

Our study revealed that having an ADR was a significant predictor and personal reason for serious interruption under MDR-TB treatment. This result concurs with previous clinical studies. ${ }^{19-21}$ A systematic review demonstrated that $57 \%$ of the patients experienced at least one kind of ADR while undergoing MDR-TB treatment, ${ }^{20}$ which is similar to our finding (51.5\%). An ADR can result in a change of regimen ${ }^{20}$ or drugs being discontinued temporarily or permanently. ${ }^{19,21}$ Amikacin was found in other studies to have a higher amount of ototoxicity than other injectable agents. ${ }^{22,23}$ Hematoma and pain at the injection site can also negatively affect treatment adherence. ${ }^{24}$ Thus, amikacin was the most interrupted drug in our study. The high rate of ADRs among MDRTB patients suggests that it is essential to monitor patients monthly during their treatment. ${ }^{2,11}$ Therefore, the use of drugs should not be considered based only on its price but also on its effect of ADRs.

In China, for each patient with MDR-TB in the first year of treatment, the estimated drug cost is about US \$2648 based on the cheapest 5-drug regimen (amikacin, pyrazinamide, levofloxacin, p-aminosalicylic acid, prothionamide), ${ }^{17}$ and up to around US $\$ 6090$ based on a preferred regimen (kanamycin, pyrazinamide, levofloxacin, cycloserine, prothionamide) stated in the national guideline. ${ }^{11}$ Kanamycin is one of the more expensive drugs and it is not included in the national essential drug list and the patient must bear the cost. Cycloserine, another costly drug, is included in the national essential drug list but is only partially reimbursed by the insurance system. The average level of per capita annual income in Guizhou in 2017 was US $\$ 4406 .{ }^{25}$
In our study, the per capita annual income of patients was only US $\$ 1761$. Thus, cheap regimens for MDR-TB patients are generally more available in Guizhou than preferred regimens. However, even though patients in our study used a less expensive regimen, more than half were in debt due to MDR-TB treatment. Consequently, cycloserine and amikacin were interrupted by some patients due to the high cost and injection fee. Previous qualitative studies showed that economic burden due to MDR-TB treatment was a reason for low enrollment ${ }^{26,27}$ and treatment interruption. ${ }^{6}$ Another study found that financial support motivated patients to improve adherence ${ }^{28}$ and had a positive effect on successful treatment. ${ }^{5}$ Therefore, revising the national essential drug list and preparing a special budget to universally cover all drugs in the list, including injection fees, may be beneficial to optimize treatment regimens and improve adherence.

Our study found that serious treatment interruption was more common in patients with a baseline co-morbidity, a result similar to other studies conducted in patients with drug-susceptible $\mathrm{TB}^{29}$ and other chronic diseases. ${ }^{30,31} \mathrm{~A}$ high pill burden due to the co-morbidity may negatively affect treatment adherence. ${ }^{30}$ The severity of symptoms may also affect treatment interruption. ${ }^{31}$ Multiple drugs can also make patients more vulnerable to ADRs, which are known to be associated with poor adherence. ${ }^{19,20,32}$ Our findings of ADRs as a major cause of drug interruption may imply the need to look for regimens with fewer ADRs.

Correct drug dosage is particularly difficult for MDRTB patients because of multiple drugs, all with a similarly high daily pill burden, long duration of treatment, frequent 
Table 4 Predictors Of Serious Treatment Interruption By Univariate And Multivariate Analysis

\begin{tabular}{|c|c|c|c|c|c|c|}
\hline \multirow[t]{2}{*}{ Characteristic } & \multirow[t]{2}{*}{ Total N (\%) } & \multicolumn{2}{|c|}{$\begin{array}{l}\text { Duration Of } \\
\text { Interruption }\end{array}$} & \multirow[t]{2}{*}{ P Value } & \multirow[t]{2}{*}{ Adjusted OR (95\% Cl) } & \multirow[t]{2}{*}{ P-Value (LR Test) } \\
\hline & & 0-14 Days & $>14$ days & & & \\
\hline Total & $202(100.0)$ & I44 (7I.3) & $58(28.7)$ & & & \\
\hline $\begin{array}{l}\text { Gender } \\
\text { Female } \\
\text { Male }\end{array}$ & $\begin{array}{l}67(33.2) \\
135(66.8)\end{array}$ & $\begin{array}{l}46(31.9) \\
98(68.1)\end{array}$ & $\begin{array}{l}21(36.2) \\
37(63.8)\end{array}$ & 0.677 & - & - \\
\hline 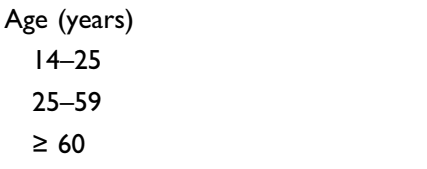 & $\begin{array}{l}47(23.3) \\
134(66.3) \\
21(10.4)\end{array}$ & $\begin{array}{l}37(25.7) \\
95(66.0) \\
12(8.3)\end{array}$ & $\begin{array}{l}10(17.2) \\
39(67.2) \\
9(15.5)\end{array}$ & 0.189 & $\begin{array}{l}\text { Ref } \\
1.23(0.52-2.89) \\
2.06(0.62-6.92)\end{array}$ & 0.497 \\
\hline $\begin{array}{l}\text { Marital status } \\
\text { Single } \\
\text { Married }\end{array}$ & $\begin{array}{l}78(38.6) \\
124(61.4)\end{array}$ & $\begin{array}{l}59(4 I) \\
85(59)\end{array}$ & $\begin{array}{l}19(32.8) \\
39(67.2)\end{array}$ & 0.355 & - & - \\
\hline Education level & & & & 0.578 & - & - \\
\hline $\begin{array}{l}\text { Primary school or less } \\
\text { Middle school } \\
\text { High school } \\
\text { University }\end{array}$ & $\begin{array}{l}60(29.7) \\
68(33.7) \\
55(27.2) \\
19(9.4)\end{array}$ & $\begin{array}{l}43(29.9) \\
49(34.0) \\
41(28.5) \\
\text { II (7.6) }\end{array}$ & $\begin{array}{l}17(29.3) \\
19(32.8) \\
14(24.1) \\
8(13.8)\end{array}$ & & & \\
\hline $\begin{array}{l}\text { Occupational status after diagnosis } \\
\text { Still working } \\
\text { Lost job or could not work } \\
\text { Student/unemployed }\end{array}$ & $\begin{array}{l}62(30.7) \\
103(51.0) \\
37(18.3)\end{array}$ & $\begin{array}{l}45(31.2) \\
71(49.3) \\
28(19.4)\end{array}$ & $\begin{array}{l}17(29.3) \\
32(55.2) \\
9(15.5)\end{array}$ & 0.713 & - & - \\
\hline $\begin{array}{l}\text { In debt due to MDR-TB } \\
\text { Yes } \\
\text { No }\end{array}$ & $\begin{array}{l}120(59.4) \\
82(40.6)\end{array}$ & $\begin{array}{l}86(59.7) \\
58(40.3)\end{array}$ & $\begin{array}{l}34(58.6) \\
24(41.4)\end{array}$ & 1.000 & - & - \\
\hline $\begin{array}{l}\text { Weight at baseline } \\
\geq 50 \mathrm{~kg} \\
<50 \mathrm{~kg}\end{array}$ & $\begin{array}{l}119(58.9) \\
83(41.1)\end{array}$ & $\begin{array}{l}89(61.8) \\
55(38.2)\end{array}$ & $\begin{array}{l}30(51.7) \\
28(48.3)\end{array}$ & 0.246 & - & - \\
\hline $\begin{array}{l}\text { Duration of treatment (months) } \\
\text { |-|I } \\
\text { |2-24 }\end{array}$ & $\begin{array}{l}60(29.7) \\
142(70.3)\end{array}$ & $\begin{array}{l}4 I(28.5) \\
103(7 I .5)\end{array}$ & $\begin{array}{l}19(32.8) \\
39(67.2)\end{array}$ & 0.665 & - & - \\
\hline $\begin{array}{l}\text { Underwent DOT } \\
\text { Yes } \\
\text { No }\end{array}$ & $\begin{array}{l}56(27.7) \\
146(72.3)\end{array}$ & $\begin{array}{l}40(27.8)) \\
104(72.2)\end{array}$ & $\begin{array}{l}16(27.6) \\
42(72.4)\end{array}$ & I & - & - \\
\hline $\begin{array}{l}\text { Monthly OOP drug expenses (US\$) } \\
\leq 250 \\
>250\end{array}$ & $\begin{array}{l}\text { I45 (7I.8) } \\
57(28.2)\end{array}$ & $\begin{array}{l}\text { II } 12(77.8) \\
32(22.2)\end{array}$ & $\begin{array}{l}33(56.9) \\
25(43.1)\end{array}$ & 0.005 & $\begin{array}{l}\text { Ref } \\
2.27(1.14-4.50)\end{array}$ & 0.020 \\
\hline $\begin{array}{l}\text { Baseline co-morbidity } \\
\text { No } \\
\text { Yes }\end{array}$ & $\begin{array}{l}162(80.2) \\
40(19.8)\end{array}$ & $\begin{array}{l}124(86.1) \\
20(13.9)\end{array}$ & $\begin{array}{l}38(65.5) \\
20(34.5)\end{array}$ & 0.002 & $\begin{array}{l}\text { Ref } \\
2.53(1.19-5.38)\end{array}$ & 0.017 \\
\hline $\begin{array}{l}\text { Any ADRs during treatment } \\
\text { No } \\
\text { Yes }\end{array}$ & $\begin{array}{l}98(48.5) \\
104(5 \mid .5)\end{array}$ & $\begin{array}{l}82(56.9) \\
62(43.1)\end{array}$ & $\begin{array}{l}16(27.6) \\
42(72.4)\end{array}$ & $<0.001$ & $\begin{array}{l}\text { Ref } \\
2.82(|.4|-5.6 \mid)\end{array}$ & 0.003 \\
\hline
\end{tabular}

Abbreviations: ADRs, adverse drug reactions; DOT, directly observed treatment; MDR-TB, multidrug-resistant tuberculosis; OOP, out-of-pocket; OR, odds ratio; Cl, confidence interval; LR test, likelihood ratio test; ref, reference group. 
Table 5 Agreement Between Self-Report And Pill Counts By Drug Received

\begin{tabular}{|c|c|c|c|c|c|}
\hline \multirow[t]{7}{*}{ Amikacin $(n=32)$} & & \multicolumn{4}{|l|}{ Pill count } \\
\hline & Self-report & Underused & Correctly used & Overused & Total (n, \%) \\
\hline & Underused & & 0 & 0 & $19(59.4)$ \\
\hline & Correctly used & & & & $8(25.0)$ \\
\hline & Overused & & 0 & & $5(15.6)$ \\
\hline & Total (n, \%) & $20(62.5)$ & $7(21.9)$ & $5(15.6)$ & $32(100.0)$ \\
\hline & \multicolumn{5}{|l|}{ Карра $=0.95$} \\
\hline \multirow[t]{7}{*}{ Levofloxacin $(n=109)$} & & \multicolumn{4}{|l|}{ Pill count } \\
\hline & Self-report & Underused & Correctly used & Overused & Total (n, \%) \\
\hline & Underused & & & & $61(56.0)$ \\
\hline & Correctly used & & 30 & & $35(32.1)$ \\
\hline & Overused & 0 & 1 & 12 & $13(11.9)$ \\
\hline & Total (n, \%) & $64(58.7)$ & $33(30.3)$ & $12(11.0)$ & $109(100.0)$ \\
\hline & \multicolumn{5}{|l|}{ Карра $=0.88$} \\
\hline \multirow[t]{7}{*}{ Prothionamide $(n=106)$} & & \multicolumn{4}{|l|}{ Pill count } \\
\hline & Self-report & Underused & Correctly used & Overused & Total (n, \%) \\
\hline & Underused & & & & $58(54.7)$ \\
\hline & Correctly used & 10 & 26 & 5 & $4 I(38.7)$ \\
\hline & Overused & & 0 & & $7(6.6)$ \\
\hline & Total (n, \%) & $68(64.2)$ & $28(26.4)$ & $10(9.4)$ & $106(100.0)$ \\
\hline & \multicolumn{5}{|l|}{ Карра $=0.69$} \\
\hline \multirow{7}{*}{$\begin{array}{l}\text { Pyrazinamide } \\
(n=105)\end{array}$} & & \multicolumn{4}{|l|}{ Pill count } \\
\hline & Self-report & Underused & Correctly used & Overused & Total (n, \%) \\
\hline & Underused & 63 & I & 0 & $64(61.0)$ \\
\hline & Correctly used & 8 & 16 & II & $35(33.3)$ \\
\hline & Overused & & I & & $6(5.7)$ \\
\hline & Total (n, \%) & 71 (67.6) & $18(17.1)$ & $16(15.2)$ & $105(100.0)$ \\
\hline & \multicolumn{5}{|l|}{ Карра $=0.69$} \\
\hline \multirow{7}{*}{$\begin{array}{l}\text { Ethambutol } \\
(n=92)\end{array}$} & & \multicolumn{4}{|l|}{ Pill count } \\
\hline & Self-report & Underused & Correctly used & Overused & Total (n, \%) \\
\hline & Underused & 49 & 3 & 0 & $52(56.5)$ \\
\hline & Correctly used & & 23 & 7 & $34(37.0)$ \\
\hline & Overused & 0 & 0 & 6 & $6(6.5)$ \\
\hline & Total (n, \%) & $53(57.6)$ & $26(28.3)$ & $13(14.1)$ & $92(100.0)$ \\
\hline & \multicolumn{5}{|l|}{ Карра $=0.78$} \\
\hline \multirow[t]{7}{*}{ P-aminosalicylic acid $(n=82)$} & & \multicolumn{4}{|l|}{ Pill count } \\
\hline & Self-report & Underused & Correctly used & Overused & Total (n, \%) \\
\hline & Underused & 42 & 3 & & $48(58.5)$ \\
\hline & Correctly used & 10 & 14 & 3 & $27(33.0)$ \\
\hline & Overused & 0 & 2 & 5 & $7(8.5)$ \\
\hline & Total & $52(63.4)$ & $19(23.2)$ & II (13.4) & $82(100.0)$ \\
\hline & Карра $=0.57$ & & & & \\
\hline
\end{tabular}

(Continued) 
Table 5 (Continued).

\begin{tabular}{|c|c|c|c|c|c|c|}
\hline \multirow{7}{*}{\multicolumn{2}{|c|}{ Cycloserine $(n=34)$}} & & \multicolumn{4}{|l|}{ Pill count } \\
\hline & & \multirow{5}{*}{$\begin{array}{l}\text { Self-report } \\
\text { Underused } \\
\text { Correctly used } \\
\text { Overused } \\
\text { Total (n, \%) }\end{array}$} & \multirow{5}{*}{$\begin{array}{l}\text { Underused } \\
14 \\
4 \\
0 \\
18(53.0)\end{array}$} & \multirow{5}{*}{$\begin{array}{l}\text { Correctly used } \\
\text { I } \\
\text { II } \\
\text { I } \\
13(38.2)\end{array}$} & Overused & Total (n, \%) \\
\hline & & & & & & $15(44.1)$ \\
\hline & & & & & & $17(50.0)$ \\
\hline & & & & & & $2(5.9)$ \\
\hline & & & & & $3(8.8)$ & $34(100)$ \\
\hline & & \multicolumn{5}{|l|}{ Kappa $=0.63$} \\
\hline \multirow{7}{*}{\multicolumn{2}{|c|}{ Amoxicillin/ Clavulanate $(n=32)$}} & & \multicolumn{4}{|l|}{ Pill count } \\
\hline & & \multirow{5}{*}{$\begin{array}{l}\text { Self-report } \\
\text { Underused } \\
\text { Correctly used } \\
\text { Overused } \\
\text { Total (n, \%) }\end{array}$} & \multirow{5}{*}{$\begin{array}{l}\text { Underused } \\
15 \\
2 \\
0 \\
17(53.1)\end{array}$} & \multirow{5}{*}{$\begin{array}{l}\text { Correctly used } \\
1 \\
10 \\
0 \\
\text { II (34.4) }\end{array}$} & Overused & Total (n, \%) \\
\hline & & & & & & $16(50.0)$ \\
\hline & & & & & 0 & $12(37.5)$ \\
\hline & & & & & 4 & $4(12.5)$ \\
\hline & & & & & $4(12.5)$ & $32(100.0)$ \\
\hline & & \multicolumn{5}{|l|}{ Kappa $=0.87$} \\
\hline \multirow{7}{*}{\multicolumn{2}{|c|}{ Clofazimine $(n=I I)$}} & & \multicolumn{4}{|l|}{ Pill count } \\
\hline & & \multirow{5}{*}{$\begin{array}{l}\text { Self-report } \\
\text { Underused } \\
\text { Correctly used } \\
\text { Overused } \\
\text { Total (n, \%) }\end{array}$} & \multirow{5}{*}{$\begin{array}{l}\text { Underused } \\
3 \\
2 \\
0 \\
5(45.5)\end{array}$} & \multirow{5}{*}{$\begin{array}{l}\text { Correctly used } \\
0 \\
5 \\
0 \\
5(45.5)\end{array}$} & Overused & Total $(\mathrm{n}, \%)$ \\
\hline & & & & & 0 & $3(27.3)$ \\
\hline & & & & & 1 & 8 (72.7) \\
\hline & & & & & & $0(0.0)$ \\
\hline & & & & & I (9.1) & II $(100.0)$ \\
\hline & & \multicolumn{5}{|l|}{ Kappa $=0.52$} \\
\hline \multirow{7}{*}{\multicolumn{2}{|c|}{ Moxifloxacin $(n=6)$}} & & \multicolumn{4}{|l|}{ Pill count } \\
\hline & & Self-report & Underused & Correctly used & Overused & Total (n, \%) \\
\hline & & Underused & 2 & 0 & 0 & $2(33.3)$ \\
\hline & & Correctly used & 0 & 3 & 0 & $3(50.0)$ \\
\hline & & Overused & 0 & I & 0 & I (I6.7) \\
\hline & & Total (n, \%) & $2(33.3)$ & $4(66.7)$ & $0(0.0)$ & $6(100.0)$ \\
\hline & & \multicolumn{5}{|l|}{ Карра $=0.73$} \\
\hline \multirow[t]{8}{*}{ Patients $(\mathrm{n}=\mathrm{II})$} & & \multicolumn{5}{|l|}{ Pill count } \\
\hline & Self-report & Correctly used & Only underuse & Only overuse & Both & Total $(\mathrm{n}, \%)$ \\
\hline & Correctly used & 4 & 2 & I & I & $8(7.2)$ \\
\hline & Only underuse & I & 53 & 0 & 9 & $63(56.8)$ \\
\hline & Only overuse & 0 & 1 & 5 & 0 & $6(5.4)$ \\
\hline & Both & I & 4 & I & 28 & $34(30.6)$ \\
\hline & Total (n, \%) & $6(5.4)$ & $60(54.1)$ & $7(6.3)$ & $38(34.2)$ & $111(100.0)$ \\
\hline & \multicolumn{6}{|l|}{ Kappa $=0.66$} \\
\hline
\end{tabular}

Notes: For k table, the row-wise gives self-report data; the column-wise gives pill count data. For each sub-table, the values in the diagonal cells from left upper corner to right lower corner indicate the number of subjects with agreement in assessment by these two methods.

and serious ADRs, and economic burden. A study from the Philippines showed that $93 \%$ of the MDR-TB patients missed a prescribed drug dose for at least one day during their treatment. ${ }^{3}$ Under-use was also a common problem in our study. Over-use among MDR-TB patients was moderate in our study, but the likelihood of drug toxicity may increase due to over-consumption. ${ }^{33}$ Thus, over-use should not be ignored. Previous studies found that self-reports tended to overestimate adherence rates due to desirability or recall bias. ${ }^{7,34}$ Although our study also showed that for each drug received, self-reports gave a higher rate of correct dosage than pill count, the two methods gave 
acceptable levels of agreement. There is no gold-standard method to measure medication adherence in any field as each method has its strengths and weaknesses. ${ }^{31}$ Adherence behavior is a dynamic process that needs to be monitored during the whole course of treatment. Our results suggest that patients' self-report, as a significant low-cost method, should be adopted by medical personnel to monitor drug adherence when patients visit the clinic monthly.

Our study has several limitations which should be acknowledged. First, the non-response rate was $13 \%$ which may have caused a small selection bias and therefore a possible underestimate of the non-adherence rate. Second, treatment adherence is a dynamic behavior and may therefore change over the 24-month treatment period. Third, recall bias is an unavoidable weakness in most studies. However, the fact that the self-reports and pill count results agreed with each other well might suggest that recall bias was not a serious issue in this study. Finally, patients who had already completed their treatment were not included in this study. Their omission may have biased our results due to their better adherence to treatment.

\section{Conclusion}

High incidences of serious treatment interruption and dosage incorrect use of anti-TB drugs among MDR-TB patients in Guizhou were found. ADRs and financial hardship were the main reasons for serious treatment interruption. Patients would be at increased risk for serious interruption if they had an ADR to any drug, had monthly OOP drug expense exceeding 250 US dollars, and had any co-morbidity prior to commencing treatment. Self-reports and pill count gave acceptable levels of agreement for most of the drugs used. These findings suggest that monitoring ADRs closely, revision of drug regimen, and financial support for MDR-TB in this study population are needed. Patient's self-reports can be a cost-saving method to monitor monthly drug under-use and over-use in clinical settings.

\section{Acknowledgments}

This study is a part of the first author's thesis in partial fulfillment of the requirements for a $\mathrm{PhD}$ at Prince of Songkla University, Thailand, and the training program for TB/MDR-TB research supported by the Fogarty International Center, Grant number D43TW009522. The study was funded by the China Medical Board, the
National Natural Science Foundation of China (grant number 81860591), and the Guizhou Science and Technology project (grant number [2016]1508). The authors thank all patients for participating in this study and all research team members for their support during data collection.

\section{Disclosure}

The authors report no conflicts of interest in this work.

\section{References}

1. World Health Organization. Global Tuberculosis Report, 2018. Geneva: WHO/CDS/TB/2018.20. Geneva, Switzerland: WHO; 2018.

2. World Health Organization. Companion Handbook to the WHO Guidelines for the Programmatic Management of Drug-resistant Tuberculosis. Geneva: WHO/HTM/TB/2014.11. Geneva, Switzerland: WHO; 2014.

3. Podewils LJ, Gler MTS, Quelapio MI, Chen MP. Patterns of treatment interruption among patients with multidrug-resistant TB (MDR TB) and association with interim and final treatment outcomes. PLoS One. 2013;8(7):e70064. doi:10.1371/journal.pone.0070064

4. Bastard M, Sanchez-Padilla E, Hewison C, et al. Effects of treatment interruption patterns on treatment success among patients with multidrug-resistant tuberculosis in Armenia and Abkhazia. J Infect Dis. 2015;211(10):1607-1615. doi:10.1093/infdis/jiu551

5. Yin J, Wang XM, Zhou L, Wei XL. The relationship between social support, treatment interruption and treatment outcome in patients with multidrug-resistant tuberculosis in China: a mixed-methods study. Trop Med Int Health. 2018;23(6):668-677. doi:10.1111/tmi.13084

6. Xl W, Yin J, Gy Z, et al. Treatment interruption and directly observed treatment of multidrug-resistant tuberculosis patients in China. Int $J$ Tuberc Lung Dis. 2015;19(4):413-419.

7. Schaefer MR, Wagoner ST, Young ME, et al. Subjective versus objective measures of medication adherence in adolescents/young adults with attention-deficit hyperactivity disorder. $J$ Dev Behavior Pediatr. 2019;40(1):54-59. doi:10.1097/DBP.0000000000000602

8. Cheng SM. Current situation and recommendation of MDR-TB prevention and control in China. Chin Trop Med. 2017;17(3):213-215.

9. Guizhou provincial health and family planning commission. Guizhou provincial TB control programme from 2016 to 2020. Document no. 55. Available from: http://www.chinatb.org/xxjlg/201712/ P020171217473860262138.pdf. Accessed September 13, 2019

10. Chen W, Lei SG, Li Y, An Z, Yang L. Analysis on implementation effect of MDR-TB global fund in Guizhou Province. China Health Care Nutr. 2014;07:3716.

11. Wang Y, Wang LX, Xu SF, et al. Treatment for MDR-TB. National Handbook for MDR-TB Control and Management, 2012. Li X. Beijing, China: Military Medical Science Press; 2012:16-18.

12. National essential drugs list issued by National Health Commission of the People's Republic of China in 2018. Available from: http://www. nhc.gov.cn/ewebeditor/uploadfile/2018/10/20181025195256627.pdf. Accessed September 13, 2019.

13. The list of medicines for national basic medical insurance, industrial injury insurance and maternity insurance. Available from: http://www. nhsa.gov.cn/art/2019/8/20/art_37_1666.html. Accessed September 13, 2019

14. Guide price list of national essential drugs issued by national development and reform commission in 2009. Available from: http://jgs.ndrc.gov.cn/ zcfg/200910/t20091002_748502.html. Accessed September 13, 2019.

15. Policy interpretation of the work plan for adjusting the national directory of insured drugs in 2019. Available from: http://www. nhsa.gov.cn/art/2019/4/17/art_38_1212.html. Accessed September 13, 2019 
16. Liang LL, Langenbrunner JC. The Long March to Universal Coverage: Lessons from China. Washington (DC): The World Bank; January 2013. Universal Health Coverage Studies Series (UNICO) UNICO Studies Series No. 9.

17. Wang LX, Xu CH, Zhao J, Chen C, Li RZ, Chen MT. Budget calculation on management of the national standard for multi-drug resistant tuberculosis. Chin Health Resour. 2011;14(4):250-253.

18. Chongsuvivatwong V. Analysis of Epidemiological Data Using $R$ and Epicalc. second ed. Thailand: Epidemiology Unit Prince of Songkla University; 2012.

19. Bloss E, Kuksa L, Holtz TH, et al. Adverse events related to multidrug-resistant tuberculosis treatment, Latvia, 2000-2004. Int J Tuberc Lung Dis. 2010;14(3):275-281.

20. Wu S, Zhang Y, Sun F, et al. Adverse events associated with the treatment of multidrug-resistant tuberculosis: a systematic review and meta-analysis. Am J Ther. 2016;23(2):e521-e530. doi:10.1097/01. mjt.0000433951.09030.5a

21. Zhang Y, Wu SS, Xia YY, et al. adverse events associated with treatment of multidrug-resistant tuberculosis in China: an ambispective cohort study. Med Sci Monit. 2017;18(23):2348-2356. doi:10.12659/MSM.904682

22. Carroll MW, Lee M, Cai Y, et al. Frequency of adverse reactions to first- and second-line anti-tuberculosis chemotherapy in a Korean cohort. Int J Tuberc Lung Dis. 2012;16(7):961-966. doi:10.5588/ ijtld.11.0044-e

23. Sturdy A, Goodman A, Jose RJ, et al. Multidrug-resistant tuberculosis (MDR-TB) treatment in the UK: a study of injectable use and toxicity in practice. J Antimicrob Chemother. 2011;66(8):1815-1820. doi:10.1093/jac/dkr221

24. Quenard F, Fournier PE, Drancourt M, Brouqui P. Role of secondline injectable antituberculosis drugs in the treatment of MDR/XDR tuberculosis. Int $J$ Antimicrob Agents. 2017;50(2):252-254. doi:10.1016/j.ijantimicag.2017.01.042

25. Bureau of Statistics of Guizhou. Guizhou Statistical Yearbook; 2018. Available from: http://42.123.101.206:81/tjnj/2018/zk/indexch.htm. Accessed September 13, 2019
26. Yang YB, Xu L, Li L Analysis of influencing factors on non-enrolment treatment of MDR-TB cases in Yunnan province. The 10th International Conference on Public Health Among Greater Mekong Sub-region Countries -Health Equity and Response to Crisis. November; 2018; Kumming, China.

27. Hutchison C, Khan MS, Yoong J, Lin X, Coker RJ. Financial barriers and coping strategies: a qualitative study of accessing multidrugresistant tuberculosis and tuberculosis care in Yunnan, China. BMC Public Health. 2017;17:221. doi:10.1186/s12889-017-4089-y

28. Deshmukh RD, Dhande DJ, Sachdeva KS, Sreenivas AN, Kumar AMV, Parmar M. Social support a key factor for adherence to multidrug-resistant tuberculosis treatment. Indian Tuberc. 2018;65(1):4147. doi:10.1016/j.ijtb.2017.08.030

29. Mekonnen HS, Azagew AW. Non-adherence to anti-tuberculosis treatment, reasons and associated factors among TB patients attending at Gondar town health centers, Northwest Ethiopia. BMC Res Notes. 2018;11:691. doi:10.1186/s13104-018-3789-4

30. Mulu Fentie A, Tadesse F, Engidawork E, Gebremedhin A. Prevalence and determinants of non-adherence to Imatinib in the first 3-months treatment among newly diagnosed Ethiopian's with chronic myeloid leukemia. PLoS One. 2019;14(3):e0213557.

31. World Health Organization. Adherence to Long-term Therapies: Evidence for Action. Geneva, Switzerland: WHO; 2003.

32. Alomar MJ. Factors affecting the development of adverse drug reactions (review article). Saudi Pharm J. 2014;22(2):83-94. doi:10.1016/j.jsps.2013.02.003

33. Wang YY, Liabsuetrakul T, Chongsuvivatwong V, et al. Under- and over-consumption intermittent TB treatment among rural TB patients in south-west China. Int J Tuberc Lung Dis. 2007;11(12):13451351:7.

34. Martelli G, Antonucci R, Mukurasi A, Zepherine H, Nöstlinger C. Adherence to antiretroviral treatment among children and adolescents in Tanzania: comparison between pill count and viral load outcomes in a rural context of Mwanza region. PLoS One. 2019;14(3): e0214014. doi:10.1371/journal.pone.0214014
Patient Preference and Adherence

\section{Publish your work in this journal}

Patient Preference and Adherence is an international, peer-reviewed, open access journal that focusing on the growing importance of patient preference and adherence throughout the therapeutic continuum. Patient satisfaction, acceptability, quality of life, compliance, persistence and their role in developing new therapeutic modalities and compounds to optimize clinical outcomes for existing disease states are major areas of interest for the journal. This journal has been accepted for indexing on PubMed Central. The manuscript management system is completely online and includes a very quick and fair peer-review system, which is all easy to use. Visit http:// www.dovepress.com/testimonials.php to read real quotes from published authors. 